\title{
Preliminary Incidence and Trends of Infections with Pathogens Transmitted Commonly Through Food — Foodborne Diseases Active Surveillance Network, 10 U.S. Sites, 2016-2019
}

\begin{abstract}
Danielle M. Tack, DVM ${ }^{1}$; Logan Ray, MPH ${ }^{1}$; Patricia M. Griffin, MD ${ }^{1}$; Paul R. Cieslak, MD 2 ; John Dunn, DVM ${ }^{3}$; Tamara Rissman, MPH ${ }^{4}$; Rachel Jervis, $\mathrm{MPH}^{5}$; Sarah Lathrop, $\mathrm{PhD}^{6}$; Alison Muse, $\mathrm{MPH}^{7}$; Monique Duwell, MD ${ }^{8}$; Kirk Smith, DVM ${ }^{9}$; Melissa Tobin-D’Angelo, MD ${ }^{10}$; Duc J. Vugia, $\mathrm{MD}^{11}$; Joanna Zablotsky Kufel, $\mathrm{PhD}^{12}$; Beverly J. Wolpert, PhD ${ }^{13}$; Robert Tauxe, $\mathrm{MD}^{1}$; Daniel C. Payne, PhD ${ }^{1}$
\end{abstract}

To evaluate progress toward prevention of enteric illnesses, the Foodborne Diseases Active Surveillance Network (FoodNet) of CDC's Emerging Infections Program monitors the incidence of laboratory-diagnosed infections caused by eight pathogens transmitted commonly through food at 10 U.S. sites.* This report summarizes preliminary 2019 data and describes changes in incidence compared with that during 2016-2018. The incidence of enteric infections caused by these eight pathogens reported by FoodNet sites in 2019 continued to increase or remained unchanged, indicating progress in controlling major foodborne pathogens in the United States has stalled. Campylobacter and Salmonella caused the largest proportion of illnesses; trends in incidence varied by Salmonella serotype. Widespread adoption of whole genome sequencing (WGS) of bacteria has improved the ability to identify outbreaks, emerging strains, and sources of pathogens. To maximize the potential of WGS to link illnesses to particular sources, testing of isolates by clinical and public health laboratories is needed. Reductions in Salmonella serotype Typhimurium suggest that targeted interventions (e.g., vaccinating chickens and other food animals) might decrease human infections. Reducing contamination during food production, processing, and preparation will require more widespread implementation of known prevention measures and of new strategies that target particular pathogens and serotypes.

Members of FoodNet conduct active, population-based surveillance for laboratory-diagnosed infections caused by Campylobacter, Cyclospora, Listeria, Salmonella, Shiga

\footnotetext{
*Connecticut, Georgia, Maryland, Minnesota, New Mexico, Oregon, Tennessee, and selected counties in California, Colorado, and New York (https://www. cdc.gov/foodnet).
}

toxin-producing Escherichia coli (STEC), Shigella, Vibrio, and Yersinia at 10 sites covering approximately $15 \%$ of the U.S. population (an estimated 49 million persons in 2018). FoodNet is a collaboration of CDC, 10 state health departments, the U.S. Department of Agriculture's Food Safety and Inspection Service (USDA-FSIS), and the Food and Drug Administration (FDA). Bacterial infections are defined as isolation of the bacteria from a clinical specimen by culture or detection of pathogen antigen, nucleic acid sequences, or, for STEC, ${ }^{\dagger}$ Shiga toxin or Shiga toxin genes, by a cultureindependent diagnostic test (CIDT). ${ }^{\S}$ A CIDT-positive-only

\footnotetext{
${ }^{\dagger}$ STEC infections are defined as identification of Shiga toxin or its genes by any laboratory.

$\S$ A CIDT detects the presence of a specific antibody or antigen or the DNA of an organism.
}

\section{INSIDE}

515 Progress Toward Maternal and Neonatal Tetanus Elimination - Worldwide, 2000-2018

521 Assessment of SARS-CoV-2 Infection Prevalence in Homeless Shelters - Four U.S. Cities, March 27-April 15, 2020

523 COVID-19 Outbreak Among Three Affiliated Homeless Service Sites - King County, Washington, 2020

527 Notes from the Field: Cholera Outbreak Zimbabwe, September 2018-March 2019

529 QuickStats

Continuing Education examination available at https://www.cdc.gov/mmwr/mmwr_continuingEducation.html

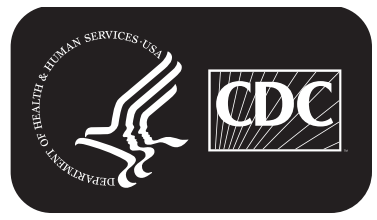

U.S. Department of Health and Human Services Centers for Disease Control and Prevention 
bacterial infection is a positive CIDT result not confirmed by culture. Listeria infections are defined as isolation of L. monocytogenes or detection of its nucleic acid sequences from a normally sterile site, or from placental or fetal tissue in the instance of miscarriage or stillbirth. Cyclospora infections are defined as detection of the parasite by microscopy using ultraviolet fluorescence or specific stains or by polymerase chain reaction. Cases with no documentation of international travel or unknown travel are considered domestically acquired infections. ${ }^{* *}$ The patient's disposition at hospital discharge, or 7 days after specimen collection if not hospitalized, is attributed to the infection.

Incidence per 100,000 population was calculated by dividing the number of infections in 2019 by the U.S. Census estimates of the surveillance area population for 2018. Incidence measures include all laboratory-diagnosed infections. A negative binomial model with $95 \%$ confidence intervals (CIs) was used to estimate change in incidence during 2019 compared with that during 2016-2018, adjusting for changes in the population over time; CIs not including zero were considered statistically significant. Analyses were performed using SAS statistical software (version 9.4; SAS Institute).

Surveillance for physician-diagnosed post-diarrheal hemolytic uremic syndrome (HUS), a complication of STEC

\footnotetext{
Serogroup or serotype is only available for infections confirmed by culture.

** No international travel or not known if international travel occurred within 30 days before illness onset for Listeria, Salmonella serotypes Typhi and Paratyphi, 15 days for Cyclospora, and 7 days for all other pathogens.
}

infection characterized by renal failure, thrombocytopenia, and microangiopathic anemia, is conducted by reviewing hospital discharge data and by working with a network of nephrologists and infection preventionists. This report includes HUS data for children for 2018, the most recent year for which data are available.

\section{Cases of Infection, Incidence, and Trends}

During 2019, FoodNet identified 25,866 cases of infection, 6,164 hospitalizations, and 122 deaths (Table 1). The overall incidence per 100,000 population was highest for Campylobacter (19.5), followed by Salmonella (17.1), STEC (6.3), Shigella (4.8), Cyclospora (1.5), Yersinia (1.4), Vibrio (0.9), and Listeria (0.3). The respective incidences were slightly lower for domestically acquired infections (Table 2). Eighty-six percent of infections were acquired domestically, ranging from $77 \%$ for Shigella to $96 \%$ for Listeria.

Compared with 2016-2018, the incidence in 2019 increased significantly for Cyclospora (1,209\%), Yersinia (153\%), Vibrio (79\%), STEC (34\%), and Campylobacter (13\%) (Table 1). The number of bacterial infections diagnosed using a CIDT increased $32 \%$, ranging from $18 \%$ for STEC to $253 \%$ for Listeria. The percentage of infections diagnosed only by CIDT, including specimens that were culture-negative and those not tested by culture, was highest for Yersinia (57\%), followed by STEC (45\%), Campylobacter (42\%), Vibrio (41\%), Shigella (40\%), Salmonella (13\%), and Listeria (1\%).

The MMWR series of publications is published by the Center for Surveillance, Epidemiology, and Laboratory Services, Centers for Disease Control and Prevention (CDC), U.S. Department of Health and Human Services, Atlanta, GA 30329-4027.

Suggested citation: [Author names; first three, then et al., if more than six.] [Report title]. MMWR Morb Mortal Wkly Rep 2020;69:[inclusive page numbers].

\section{Centers for Disease Control and Prevention}

Robert R. Redfield, MD, Director

Anne Schuchat, MD, Principal Deputy Director

Chesley L. Richards, MD, MPH, Deputy Director for Public Health Science and Surveillance

Rebecca Bunnell, PhD, MEd, Director, Office of Science

Arlene Greenspan, PhD, Acting Director, Office of Science Quality, Office of Science

Michael F. Iademarco, MD, MPH, Director, Center for Surveillance, Epidemiology, and Laboratory Services

MMWR Editorial and Production Staff (Weekly)

Charlotte K. Kent, PhD, MPH, Editor in Chief Jacqueline Gindler, MD, Editor

Paul Z. Siegel, MD, MPH, Guest Associate Editor

Mary Dott, MD, MPH, Online Editor

Terisa F. Rutledge, Managing Editor

Douglas W. Weatherwax, Lead Technical Writer-Editor

Glenn Damon, Soumya Dunworth, PhD, Teresa M. Hood, MS, Technical Writer-Editors

Michelle E. Bonds, MBA

Matthew L. Boulton, MD, MPH

Carolyn Brooks, $\mathrm{ScD}$, MA

Jay C. Butler, MD

Virginia A. Caine, MD
Martha F. Boyd, Lead Visual Information Specialist Maureen A. Leahy, Julia C. Martinroe, Stephen R. Spriggs, Tong Yang, Visual Information Specialists

Quang M. Doan, MBA, Phyllis H. King,

Terraye M. Starr, Moua Yang,

Information Technology Specialists

MMWR Editorial Board

Timothy F. Jones, MD, Chairman

Katherine Lyon Daniel, PhD

Jonathan E. Fielding, MD, MPH, MBA

David W. Fleming, MD

William E. Halperin, MD, DrPH, MPH

Jewel Mullen, MD, MPH, MPA

Jeff Niederdeppe, $\mathrm{PhD}$

\author{
Patricia Quinlisk, MD, MPH \\ Patrick L. Remington, MD, MPH \\ Carlos Roig, MS, MA \\ William Schaffner, MD \\ Morgan Bobb Swanson, BS
}


TABLE 1. Number of laboratory-diagnosed bacterial and parasitic infections, hospitalizations, and deaths, incidence and percentage change compared with 2016-2018 average annual incidence rate, by pathogen -10 U.S. sites, Foodborne Diseases Active Surveillance Network,* 2016-2019'

\begin{tabular}{|c|c|c|c|c|c|}
\hline \multirow[b]{2}{*}{ Pathogen } & \multicolumn{4}{|c|}{2019} & \multirow{2}{*}{$\begin{array}{l}\% \text { Change in incidence from } \\
2016-2018 \text { to } 2019(95 \% \text { CI })^{9}\end{array}$} \\
\hline & No. of infections & No. of hospitalizations (\%) & No. of deaths (\%) & Incidence ${ }^{\S}$ & \\
\hline \multicolumn{6}{|l|}{ Bacteria } \\
\hline Campylobacter & 9,731 & $1,988(20)$ & $26(0.3)$ & 19.5 & 13 (5 to 21$)$ \\
\hline Salmonella & 8,556 & $2,430(28)$ & $46(0.5)$ & 17.1 & $5(-1$ to 12$)$ \\
\hline STEC & 3,127 & $660(21)$ & $10(0.3)$ & 6.3 & 34 (14 to 58$)$ \\
\hline Shigella & 2,416 & 644 (27) & $3(0.1)$ & 4.8 & $7(-17$ to 37$)$ \\
\hline Yersinia & 681 & $142(21)$ & $4(0.6)$ & 1.4 & 153 (102 to 217$)$ \\
\hline Vibrio & 466 & $131(28)$ & $12(2.6)$ & 0.9 & 79 (47 to 117$)$ \\
\hline Listeria & 134 & $131(98)$ & $21(16)$ & 0.3 & 1 (-19 to 27$)$ \\
\hline \multicolumn{6}{|l|}{ Parasite } \\
\hline Cyclospora & 755 & $38(5)$ & $0(0)$ & 1.5 & $1,209$ (708 to 2,020$)$ \\
\hline Total & 25,866 & $6,164(24)$ & $122(0.5)$ & N/A & N/A \\
\hline
\end{tabular}

Abbreviations: $\mathrm{Cl}$ = confidence interval; N/A = not applicable; STEC = Shiga toxin-producing Escherichia coli.

* Data collected from laboratories in Connecticut, Georgia, Maryland, Minnesota, New Mexico, Oregon, Tennessee, and selected counties in California, Colorado, and New York.

† Data are preliminary.

$\S$ Cases per 100,000 population.

ๆ Percentage change reported as increase or decrease. Cls not including zero are statistically significant.

Overall, culture was attempted on $75 \%$ of positive bacterial CIDT results, ranging from $63 \%$ for Campylobacter to $100 \%$ for Listeria (Figure).

Among 6,656 (90\%) fully serotyped Salmonella isolates, the six most common serotypes were Enteritidis (2.6 per 100,000 population); Newport (1.4); Typhimurium (1.3); Javiana (1.1); I 4,[5],12:i:- (0.7); and Infantis (0.5). Compared with 20162018, incidence was significantly lower for Typhimurium (13\% decrease; $95 \% \mathrm{CI}=1-24)$ and I 4,[5],12:i:- (28\% decrease; $95 \% \mathrm{CI}=8-44)$; Infantis was significantly higher $(69 \%$ increase; $95 \% \mathrm{CI}=31-118)$.

Among 1,725 STEC isolates, most (397; 23\%) were O157, followed by O103 (305; 18\%), O26 (254; 15\%), and O111 $(175 ; 10 \%)$. The incidence of STEC O157 infections ( 0.8 per $100,000)$ decreased by $20 \%(95 \% \mathrm{CI}=3-34)$, compared with that during 2016-2018; the incidence of non-O157 STEC infections (2.7) increased by 35\% (95\% CI $=18-56)$.

FoodNet identified 62 cases of post-diarrheal HUS in children $(0.6$ cases per 100,000$)$ during $2018 ; 31$ (50\%) cases occurred in children aged $<5$ years $(1.1$ cases per 100,000). These rates were not significantly different from those during 2015-2017.

\section{Discussion}

In 2019, compared with the previous 3 years, the incidence of infections caused by pathogens transmitted commonly through food increased (for Campylobacter, Cyclospora, STEC, Vibrio, Yersinia) or remained unchanged (for Listeria, Salmonella,
TABLE 2. Number, percentage of all cases, and incidence of domestically acquired* laboratory-diagnosed bacterial and parasitic infections in 2019, by pathogen - 10 U.S. sites, Foodborne Diseases Active Surveillance Network, ${ }^{\dagger} 2019^{\S}$

\begin{tabular}{lcc}
\hline & \multicolumn{2}{c}{ Domestically acquired cases } \\
\cline { 2 - 3 } Pathogen & No. (\% of all cases) & Incidence $^{\text {*** }}$ \\
\hline Bacteria & & \\
Campylobacter & $8,264(85)$ & 16.5 \\
Salmonella & $7,677(90)$ & 15.4 \\
STEC & $2,514(80)$ & 5.0 \\
Shigella & $1,860(77)$ & 3.7 \\
Yersinia & $646(95)$ & 1.3 \\
Vibrio & $420(90)$ & 0.8 \\
Listeria & $129(96)$ & 0.3 \\
Parasite & & \\
Cyclospora & $646(86)$ & 1.3 \\
Total & $\mathbf{2 2 , 1 5 6 ( 8 6 )}$ & N/A \\
\hline Abbreviations: & &
\end{tabular}

Abbreviations: N/A = not applicable; STEC = Shiga toxin-producing Escherichia coli. * Includes patients who did not have international travel in the 30 days before illness onset for Listeria and Salmonella serotypes Typhi and Paratyphi; 15 days for Cyclospora; and 7 days for all other pathogens and patients for whom information on international travel was not available. Information on international travel was available for $79 \%-89 \%$ of patients with Campylobacter, Listeria, Salmonella, Shigella, Vibrio, and Yersinia infections, and for $90 \%$ or more of patients with Cyclospora and STEC infection.

† Data collected from laboratories in Connecticut, Georgia, Maryland, Minnesota, New Mexico, Oregon, Tennessee, and selected counties in California, Colorado, and New York.

$\S$ Data are preliminary.

"Denominator is all cases, including those for which information on international travel was not available. Among patients with travel information available, the percentages of domestically acquired cases were as follows: Campylobacter (81\%), Cyclospora (84\%), Listeria (95\%), Salmonella (87\%), Shigella (72\%), STEC (78\%), Vibrio (89\%), and Yersinia (94\%).

** Cases per 100,000 population. 
FIGURE. Number of infections diagnosed by culture or culture-independent diagnostic tests (CIDTs), by pathogen, year, and culture status 10 U.S. sites, Foodborne Diseases Active Surveillance Network,* 2016-2019 ${ }^{\dagger}$
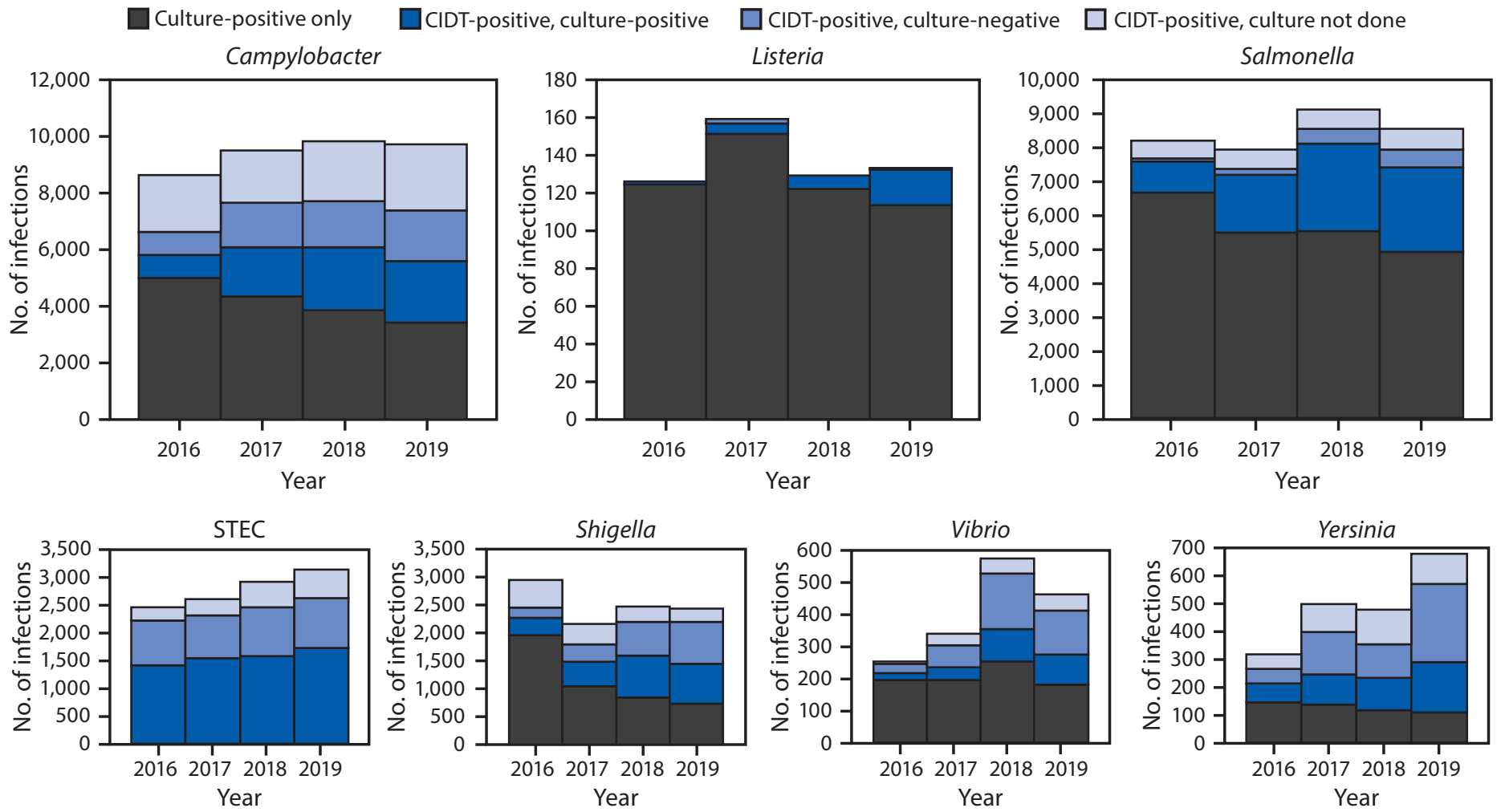

Abbreviation: STEC = Shiga toxin-producing Escherichia coli.

* Data collected from laboratories in Connecticut, Georgia, Maryland, Minnesota, New Mexico, Oregon, Tennessee, and selected counties in California, Colorado, and New York.

† Data for 2019 are preliminary.

Shigella). These data indicate that Healthy People 2020 targets for reducing foodborne illness will not be met. The identification of infections that might not have been detected before adoption of CIDTs cannot explain this overall lack of progress. Better implementation of known prevention approaches and new strategies is needed to overcome the continued challenges to reducing foodborne illnesses.

Serotype Enteritidis has been the most common cause of Salmonella infections at FoodNet sites since 2007 and incidence has not decreased. Eggs were the major source of Enteritidis infections in the 1980s (1). Chicken was recognized as another important source during the late 1990s (2,3). Infantis moved from the ninth most common Salmonella serotype among infected persons during 1996-1998 to the sixth most common in 2019. Many infections are now caused by a new, highly resistant strain found in chicken $(4,5)$. The incidence of some serotypes has declined. Typhimurium moved from the most common serotype during 1996-1998 to the third most common in 2019. Heidelberg, the third most common serotype during 1996-1998, is no longer among the top 20. These decreases might be partly related to the widespread practice of vaccinating chickens against Typhimurium, which shares antigens with Heidelberg (6). This observation, combined with a marked decline in Enteritidis infections in the United Kingdom after implementation of widespread chicken vaccination and improved farm hygiene (7), suggests that targeting other serotypes through poultry vaccination could be one way to reduce human illnesses in the United States.

Laboratory-diagnosed non-O157 STEC infections continue to increase. Although STEC O157 infections appear to be decreasing, outbreaks linked to leafy greens continue (8). Produce is also an important source for Cyclospora, Listeria, and Salmonella $(9,10)$. Although adoption of syndromic panels ${ }^{\dagger \dagger}$ could be contributing to the large increase in Cyclospora, increased exposure to this pathogen cannot be excluded. Continued implementation of FDA's Produce Safety Rule ${ }^{\S}$ (e.g., expanded surveillance inspections of foreign

\footnotetext{
†† Syndromic panels are commercial CIDTs that simultaneously detect multiple pathogens associated with clinical syndromes, such as diarrheal illness.

$\$ \$$ https://www.fda.gov/Food/GuidanceRegulation/FSMA/ucm334114.htm.
} 


\section{Summary}

What is already known about this topic?

The incidence of most infections transmitted commonly through food has not declined for many years.

What is added by this report?

Incidence of infections caused by Listeria, Salmonella, and Shigella remained unchanged, and those caused by all other pathogens reported to FoodNet increased during 2019. Infections caused by Salmonella serotype Enteritidis, did not decline; however, serotype Typhimurium infections continued to decline.

What are the implications for public health practice?

New strategies that target particular serotypes and more widespread implementation of known prevention measures are needed to reduce Salmonella illnesses. Reductions in Salmonella serotype Typhimurium suggest that targeted interventions (e.g., vaccinating chickens and other food animals) might decrease human infections. Isolates are needed to subtype bacteria so that sources of illnesses can be determined.

and domestically grown produce) is needed, as are innovative approaches for preventing contamination.

Advances in laboratory science continue to revolutionize enteric disease clinical diagnostics and surveillance. Many laboratories now use CIDTs to detect infections that would have previously been undiagnosed. In 2019, public health laboratories fully transitioned the standard subtyping method for clinical bacterial isolates from pulsed-field gel electrophoresis to WGS. WGS provides detailed information to more effectively recognize outbreaks, determine resistance patterns, and investigate reoccurring, emerging, and persisting strains. However, because CIDTs do not yield isolates needed to perform WGS, the full potential of these new technologies can only be realized when laboratories are fully able to culture CIDT-positive specimens.

The findings in this report are subject to at least three limitations. First, part of the observed increase in incidence is likely due to increased use of CIDTs that identify previously unrecognized infections. Changes in clinicians' ordering practices and varying test sensitivities and specificities might also contribute to this observation. Second, changes in health care-seeking behavior, access to health services, or other population characteristics might have changed. Finally, year-to-year changes in incidence might not reflect sustained trends.

The landscape of foodborne disease continues to change, as do the methods to determine the incidence and sources of these infections. FoodNet surveillance data indicate that progress in controlling major foodborne pathogens in the United States has stalled. To better protect the public and achieve forthcoming Healthy People 2030 foodborne disease reduction goals, more widespread implementation of known prevention measures and new strategies that target particular pathogens and serotypes are needed.

\section{Acknowledgments}

Work group members, Foodborne Diseases Active Surveillance Network (FoodNet), Emerging Infections Program, CDC; Sue Montgomery, Division of Parasitic Diseases and Malaria, Center for Global Health, CDC; Robert Breazu, Staci Dixon, Brian Katzowitz, Ellyn Marder, Hazel Shah, Division of Foodborne, Waterborne, and Environmental Diseases, National Center for Emerging and Zoonotic Infectious Diseases, CDC.

Corresponding author: Danielle M. Tack, dot7@cdc.gov, 404-718-3254.

\footnotetext{
${ }^{1}$ Division of Foodborne, Waterborne, and Environmental Diseases, National Center for Emerging and Zoonotic Infectious Diseases, CDC; ${ }^{2}$ Oregon Health Authority; ${ }^{3}$ Tennessee Department of Health; ${ }^{4}$ Connecticut Emerging Infections Program; ${ }^{5}$ Colorado Department of Public Health and Environment; ${ }^{6}$ University of New Mexico, Albuquerque; ${ }^{7} \mathrm{New}$ York State Department of Health; ${ }^{8}$ Maryland Department of Health; ${ }^{9}$ Minnesota Department of Health; ${ }^{10}$ Georgia Department of Public Health; ${ }^{11}$ California Department of Public Health; ${ }^{12}$ Food Safety and Inspection Service, U.S. Department of Agriculture, Washington, DC; ${ }^{13}$ Center for Food Safety and Applied Nutrition, Food and Drug Administration, Silver Spring, Maryland.
}

All authors have completed and submitted the International Committee of Medical Journal Editors form for disclosure of potential conflicts of interest. No potential conflicts of interest were disclosed.

\section{References}

1. Braden CR. Salmonella enterica serotype Enteritidis and eggs: a national epidemic in the United States. Clin Infect Dis 2006;43:512-7. https:// doi.org/10.1086/505973

2. Chai SJ, White PL, Lathrop SL, et al. Salmonella enterica serotype Enteritidis: increasing incidence of domestically acquired infections. Clin Infect Dis 2012;54(Suppl 5):S488-97. https://doi.org/10.1093/cid/cis231

3. Kimura AC, Reddy V, Marcus R, et al.; Emerging Infections Program FoodNet Working Group. Chicken consumption is a newly identified risk factor for sporadic Salmonella enterica serotype Enteritidis infections in the United States: a case-control study in FoodNet sites. Clin Infect Dis 2004;38(Suppl 3):S244-52. https://doi.org/10.1086/381576

4. Brown AC, Chen JC, Watkins LKF, et al. CTX-M-65 extended-spectrum B-lactamase-producing Salmonella enterica serotype Infantis, United States. Emerg Infect Dis 2018;24:2284-91. https://doi.org/10.3201/ eid2412.180500

5. The National Antimicrobial Resistance Monitoring System. NARMS integrated report, 2016-2017. Laurel, MD: US Department of Health and Human Services, Food and Drug Administration; 2019. https://www. fda.gov/animal-veterinary/national-antimicrobial-resistance-monitoringsystem/2016-2017-narms-integrated-summary

6. Dórea FC, Cole DJ, Hofacre C, et al. Effect of Salmonella vaccination of breeder chickens on contamination of broiler chicken carcasses in integrated poultry operations. Appl Environ Microbiol 2010;76:7820-5. https://doi.org/10.1128/AEM.01320-10

7. O'Brien SJ. The "decline and fall" of nontyphoidal Salmonella in the United Kingdom. Clin Infect Dis 2013;56:705-10. https://doi. org/10.1093/cid/cis967

8. CDC. Reports of E. coli outbreak investigations from 2019. Atlanta, GA: US Department of Health and Human Services, CDC; 2019. https:// www.cdc.gov/ecoli/2019-outbreaks.html 
9. CDC. Domestically acquired cases of cyclosporiasis-United States, May-August 2019. Atlanta, GA: US Department of Health and Human Services, CDC; 2019. https://www.cdc.gov/parasites/cyclosporiasis/ outbreaks/2019/a-050119/index.html
10. Interagency Food Safety Analytics Collaboration. Foodborne illness source attribution estimates for 2017 for Salmonella, Escherichia coli O157, Listeria monocytogenes, and Campylobacter using multi-year outbreak surveillance data, United States. Atlanta, GA: US Department of Health and Human Services, CDC; Silver Spring MD: US Department of Health and Human Services, Food and Drug Administration; Washington, DC: US Department of Agriculture, Food Safety and Inspection Service; 2019. https://www.cdc.gov/foodsafety/ifsac/pdf/ P19-2017-report-TriAgency-508-revised.pdf 